\title{
Diagnostic and Prognostic Value of Plasma Adrenomedullin in COPD Exacerbation
}

\author{
Da-Quan Meng MD, Xiao-Juan Li MD, Xin-Yu Song MD, \\ Jian-Bao Xin MD, and Wei-Bing Yang MD
}

\begin{abstract}
BACKGROUND: Adrenomedullin (ADM) is a regulatory peptide with many biological actions, but little is known about its role in patients with COPD exacerbation. The purpose of this study was to evaluate the diagnostic and prognostic value of plasma ADM levels on hospital admission in patients with COPD exacerbation. METHODS: Consecutive subjects admitted to the hospital for COPD exacerbation were included and were followed up for $1 \mathrm{y}$; in addition, subjects with stable COPD from an out-patient clinic and healthy volunteers were recruited as controls. RESULTS: Compared with healthy subjects $(145 \mathrm{pg} / \mathrm{mL}$ [interquartile range $\{I Q R\} 103-290 \mathrm{pg} / \mathrm{mL}])$, plasma ADM levels were significantly higher in subjects with COPD exacerbation $(270 \mathrm{pg} / \mathrm{mL}$ [IQR $170-510 \mathrm{pg} / \mathrm{mL}]$, $P=.001)$ and in subjects with stable COPD $(400 \mathrm{pg} / \mathrm{mL}[\mathrm{IQR} 210-525 \mathrm{pg} / \mathrm{mL}], P<.001)$. In subjects with COPD exacerbation, ADM levels were significantly elevated during exacerbation (560 $\mathrm{pg} / \mathrm{mL}$ [IQR 495-630 pg/mL]) compared with the recovery phase $(470 \mathrm{pg} / \mathrm{mL}$ [IQR 393-553 pg/mL], $P=.01)$ and the stable phase $(200 \mathrm{pg} / \mathrm{mL}[\mathrm{IQR} 143-308 \mathrm{pg} / \mathrm{mL}], P<.001)$. In receiver operating characteristic analysis, in subjects with COPD exacerbation, ADM had high diagnostic accuracy in differentiating between exacerbation and the stable phase (area under the curve $0.97,95 \%$ CI $0.93-1.02, P<.001)$. In Cox regression analysis, plasma ADM was not independently associated with 1-y survival $(P=.97)$, but it could accurately predicted the need for ICU care (hazard ratio $1.37,95 \%$ CI 1.09-1.72, $P=.008$ ). CONCLUSIONS: Plasma ADM is a valuable biomarker to confirm COPD exacerbation; furthermore, plasma ADM independently predicts the need of ICU care, although it is not associated with long-term mortality in patients with COPD exacerbation. Key words: chronic obstructive pulmonary disease; COPD; exacerbation; adrenomedullin; diagnosis; prognosis. [Respir Care 2014;59(10):1542-1549. (C) 2014 Daedalus Enterprises]
\end{abstract}

\section{Introduction}

COPD is the fourth leading cause of death worldwide, and it is predicted to be the third leading cause by the year

\footnotetext{
Drs Meng, Xin, and Yang are affiliated with the Department of Respiratory and Critical Care Medicine, Union Hospital, Tongji Medical College, Huazhong University of Science and Technology, Wuhan, China. $\mathrm{Dr} \mathrm{Li}$ is affiliated with the Department of Respiratory Diseases, First Hospital of Yichang, People's Hospital of Three Gorges University, Yichang, China. Dr Song is affiliated with the Department of Respiratory Diseases, Yichang Central Hospital, First Medical College of Three Gorges University, Yichang, China.
}

Drs Meng and Li are co-first authors.

This work was supported by special funds for chronic respiratory disease research in clinical medicine from the Chinese Medical Association. The authors have disclosed no conflicts of interest.
2020. ${ }^{1}$ Exacerbations are important events in the chronic and progressive course of COPD. ${ }^{2}$ Frequent exacerbations could reduce quality of life, speed disease progression, and increase the risk of death. ${ }^{3}$ Exacerbation management usually requires medical care, and severe exacerbations frequently require hospital admission. Several systemic biomarkers are increased during exacerbations, and some of them have been identified as valuable tools for disease diagnosis $^{4}$ and outcome prediction ${ }^{5}$ in the stable stage.

\footnotetext{
Correspondence: Wei-Bing Yang MD, Department of Respiratory and Critical Care Medicine, Union Hospital, Tongji Medical College, Huazhong University of Science and Technology, 1277 Jiefang Avenue, Wuhan 430022, China. E-mail: wbingyang@aliyun.com.
}

DOI: $10.4187 /$ respcare. 03046 


\section{Diagnostic and Prognostic Value of Plasma ADM in COPD Exacerbation}

However, whether these biomarkers have diagnostic or prognostic value for exacerbations is not clear.

Although COPD exacerbation was defined in $2000,{ }^{6}$ it is difficult in clinical practice to reliably distinguish between exacerbation and the stable stage because this definition is based on the patient's symptom changes and requires subjective assessment by the patient and the physician. It is now widely recognized that COPD is associated with systemic inflammation, and several circulating biomarkers are increased at the time of exacerbation. Within this context, there has been great interest in developing a biomarker that is present at different concentrations on exacerbation and in stable disease. One biomarker of interest is adrenomedullin (ADM), a peptide that has a range of biological functions.

$\mathrm{ADM}$ is a 52-amino acid peptide that was first isolated from human pheochromocytoma. ${ }^{7}$ It can be synthesized by many tissues and cells, such as the adrenal medulla, myocardium, central nervous system, and vascular smooth muscle cells. ${ }^{8}$ ADM has a variety of biological actions, including vasodilatory, ${ }^{9}$ bactericidal, ${ }^{10}$ and anti-inflammatory activities. ${ }^{11}$ Plasma ADM has been shown to be elevated in a number of diseases, such as arterial hypertension, ${ }^{12}$ myocardial infarction, ${ }^{13}$ heart failure, ${ }^{14}$ renal diseases, ${ }^{15}$ and septic shock. ${ }^{16}$ Furthermore, it is involved in the pathophysiology of these disorders. An earlier study described increased ADM levels in patients with COPD, ${ }^{17}$ but its mechanism of action in this disease remains unclear.

The utility of plasma ADM levels in disease diagnosis has been discussed in acute dyspnea ${ }^{18}$ and sepsis, ${ }^{19}$ and plasma ADM levels have been shown to be helpful in the early diagnosis of sepsis. In addition, plasma ADM concentrations have also been found to predict prognosis in patients with acute myocardial infarction ${ }^{20}$ and community-acquired pneumonia. ${ }^{21}$ However, there is little information about the use of ADM levels in patients with COPD.

Therefore, in this study, we aimed to investigate the diagnostic and prognostic value of plasma ADM levels on hospital admission in patients with COPD exacerbation. First, we tried to evaluate the diagnostic accuracy of ADM in patients with COPD requiring hospitalization for exacerbation. Second, we sought to assess the predictive ability of ADM for long-term outcome in the same patients.

\section{Methods}

\section{Study Design and Subjects}

From May 1, 2011, to May 31, 2012, all subjects with COPD exacerbation admitted to the Respiratory Department of Union Hospital in Wuhan, China, were included in this study. In addition, subjects with stable COPD from the out-patient clinic and healthy volunteers were recruited as controls. The diagnosis of COPD was based on clinical

\section{QUICK LOOK}

\section{Current knowledge}

Adrenomedullin (ADM) is a regulatory peptide with vasodilatory, bactericidal, and anti-inflammatory activity. Little is known about the role of ADM in patients with COPD exacerbation.

\section{What this paper contributes to our knowledge}

Plasma ADM is a valuable biomarker to confirm COPD exacerbation. Additionally, plasma ADM levels independently predict the need for ICU admission, although they are not associated with long-term mortality.

history, physical examination, spirometry, and chest radiographs. COPD exacerbation is defined as a sustained worsening of a patient's condition (from the stable state and beyond normal day-to-day variations) that is acute in onset and necessitates a change in regular medication in a patient with underlying COPD. ${ }^{6}$ Stable COPD is defined as the time point of inclusion without any reported worsening of a patient's condition beyond normal day-to-day variations and with no change in regular medication in the preceding $30 \mathrm{~d}$. Subjects were excluded if they had significant comorbidities, including tuberculosis, any lung disease other than COPD, coronary artery disease, congestive heart failure, liver or renal impairment or failure, diabetes mellitus, cancer, or collagen and vascular disorders.

Subjects with COPD exacerbation were examined on admission by a specialist in pulmonary medicine. The baseline assessment included the gathering of clinical data and the performance of routine blood tests. Blood for ADM measurement was drawn immediately after admission and before the administration of any drug therapy and then stored at $-80^{\circ} \mathrm{C}$ for subsequent analysis. Anthonisen criteria and exacerbation type were recorded. ${ }^{22}$ Spirometry was performed during hospitalization when available. The severity of COPD was classified according to the Global Initiative for Chronic Obstructive Lung Disease (GOLD) grades. ${ }^{23}$ After full recovery, during out-patient visits, some subjects were re-evaluated at 14-21 d (recovery phase) and 6 months (stable phase) after the initial hospital admission; their blood samples for ADM measurement were collected at the same time.

All subjects with COPD exacerbation were followed until September 31, 2013. The primary end point of this study was all-cause mortality during $1 \mathrm{y}$ of follow-up. The secondary end point was the need for ICU care during the initial hospitalization. Survival status and death dates were obtained based on review of medical records and personal interviews with subjects or their families. Medical record 


\section{Diagnostic and Prognostic Value of Plasma ADM in COPD Exacerbation}

review was performed by 2 independent pulmonary specialists. Discrepancies were settled by consensus.

The study was carried out according to the principles of the Declaration of Helsinki and was approved by our local ethics committee. Written informed consent was obtained from all participants.

\section{Measurements}

Adrenomedullin was detected in the plasma of all subjects with an enzyme immunoassay kit (Phoenix Pharmaceuticals, Burlingame, California). The lower detection limit of the assay is $0.13 \mathrm{ng} / \mathrm{mL}$, and the assay range is 0-100 ng/mL. Arterial blood gases $\left(\mathrm{P}_{\mathrm{aCO}_{2}}\right.$ and $\left.\mathrm{P}_{\mathrm{aO}}\right)$, leukocyte counts, and serum $\mathrm{C}$-reactive protein levels were recorded from the hospital records.

\section{Statistical Analyses}

Discrete variables are expressed as counts (percentages), and continuous variables are expressed as means \pm SD or median (interquartile range [IQR]). Comparability of groups was analyzed by chi-square test, 2-sample $t$ test, Mann-Whitney U test, Kruskal-Wallis analysis of variance, Wilcoxon signed-rank test, or Friedman test as appropriate. Receiver operating characteristic curve analyses with area under the curve were constructed to evaluate the diagnostic accuracy of ADM for COPD exacerbation. Correlation analyses were performed using the Spearman rank correlation. Cox regression univariate and multivariate analyses were applied to assess the influence of age, gender, body mass index, leukocyte counts, C-reactive protein, percent-of-predicted $\mathrm{FEV}_{1}, \mathrm{P}_{\mathrm{aO}_{2}}, \mathrm{P}_{\mathrm{aCO}_{2}}$, and ADM levels at admission on 1-y survival and to identify independent predictors for the need for ICU care. Skewed data were logarithmically transformed for regression analyses. Statistical analyses were performed using SPSS 19.0 (SPSS, Chicago, Illinois). All tests were 2-tailed, and $P<.05$ was regarded as statistically significant.

\section{Results}

Seventy-nine subjects with COPD exacerbation were included, and 29 subjects with stable COPD and 20 healthy volunteers were also enrolled. The detailed baseline characteristics of the 128 subjects are presented in Table 1. For subjects with COPD exacerbation, the main cause of exacerbations was infection (72.2\%), diagnosed by the isolation of bacterial pathogens in sputum culture or by the presence of purulent sputum and fever. Other causes of exacerbations were inhalation of cold air or particles $(19.0 \%)$, non-adherence to inhaled medication $(6.3 \%)$, and pneumothorax $(2.5 \%)$. Mean age at inclusion was $67.0 \mathrm{y}$. Spirometry measurement during hospitalization was avail- able for 58 subjects. The mean \pm SD percent-of-predicted $\mathrm{FEV}_{1}$ was $35.05 \pm 17.98 \%$, and the mean $\pm \mathrm{SD} \mathrm{FEV}_{1} / \mathrm{FVC}$ was $0.45 \pm 0.13$. According to Anthonisen criteria, exacerbation were graded as type 1 in 22 subjects $(27.8 \%)$, as type 2 in 24 subjects (30.4\%), and as type 3 in 33 subjects (41.8\%). The median hospital stay was $9 \mathrm{~d}$ (IQR 6-13 d). Four subjects $(5.0 \%)$ died in the hospital. There were another 9 deaths during the follow-up period. Thus, 13 subjects $(16.5 \%)$ died within $1 \mathrm{y}$ of the initial hospitalization. In addition, 30 subjects (38.0\%) required a re-hospitalization due to exacerbation within $1 \mathrm{y}$ of follow-up. For subjects with stable COPD, the mean age at inclusion was 64.9 y. The mean \pm SD percent-of-predicted $\mathrm{FEV}_{1}$ was $34.94 \pm 13.18 \%$, and the mean $\pm \mathrm{SD} \mathrm{FEV}_{1} / \mathrm{FVC}$ was $0.37 \pm 0.09$. According to the GOLD criteria, 5 subjects $(17.2 \%)$ were GOLD 2, 12 subjects $(41.4 \%)$ were GOLD 3, and 12 subjects (41.4\%) were GOLD 4. For healthy volunteers, the mean age at inclusion was $61.6 \mathrm{y}$, the mean $\pm \mathrm{SD}$ percent-of-predicted $\mathrm{FEV}_{1}$ was $103.33 \pm 8.42 \%$, and the mean $\pm \mathrm{SD} \mathrm{FEV}_{1} / \mathrm{FVC}$ was $0.80 \pm 0.04$.

In subjects with COPD exacerbation, although a correlation was found between ADM levels at hospital admission and COPD severity according to the GOLD criteria ( $\mathrm{r}=0.28, P=.03$ ), the ADM levels did not discriminate between different GOLD grades $(P=.13)$ : ADM levels in subjects with GOLD 2 were $175 \mathrm{pg} / \mathrm{mL}$ (IQR 115-355 $\mathrm{pg} / \mathrm{mL}$ ), with GOLD 3 were $285 \mathrm{pg} / \mathrm{mL}$ (IQR 163-580 $\mathrm{pg} / \mathrm{mL}$ ), and with GOLD 4 were $380 \mathrm{pg} / \mathrm{mL}$ (IQR 205$615 \mathrm{pg} / \mathrm{mL}$ ). Similarly, there were no differences between 3 Anthonisen exacerbation types $(P=.55)$ : ADM levels for subjects with type 1 were $255 \mathrm{pg} / \mathrm{mL}$ (IQR 165-408 $\mathrm{pg} / \mathrm{mL}$ ), with type 2 were $240 \mathrm{pg} / \mathrm{mL}$ (IQR $155-535 \mathrm{pg} /$ $\mathrm{mL}$ ), and with type 3 were $420 \mathrm{pg} / \mathrm{mL}$ (IQR 170-570 $\mathrm{pg} / \mathrm{mL}$ ). As shown in Table 2, a significant correlation was observed between ADM levels on hospital admission and smoking history ( $\mathrm{r}=0.23, P=.04)$, but there was no correlation between ADM levels and leukocyte counts $(\mathrm{r}=0.11, P=.33)$, C-reactive protein $(\mathrm{r}=0.02, P=.90)$, $\mathrm{P}_{\mathrm{aO}_{2}}(\mathrm{r}=-0.20, P=.10), \mathrm{P}_{\mathrm{aCO}_{2}}(\mathrm{r}=0.11, P=.39)$, or percent-of-predicted $\mathrm{FEV}_{1}(\mathrm{r}=-0.18, P=.19)$.

Compared with healthy individuals $(145 \mathrm{pg} / \mathrm{mL}$ [IQR $103-290 \mathrm{pg} / \mathrm{mL}]$ ), ADM levels were significantly higher in subjects with COPD exacerbation $(270 \mathrm{pg} / \mathrm{mL}$ [IQR $170-510 \mathrm{pg} / \mathrm{mL}], P=.001)$ and in subjects with stable COPD (400 pg/mL [IQR 210-525 pg/mL], $P<.001$ ) (Fig. 1A). Although subjects with stable COPD seemed to have higher ADM concentrations than COPD exacerbation, it was not significant $(P=.26)$. For subjects with COPD exacerbation, blood drawn for ADM analysis in 3 phases was available for 20 subjects. ADM levels were significantly elevated during exacerbation $(560 \mathrm{pg} / \mathrm{mL}$ [IQR 495-630 pg/mL]) compared with the recovery phase (470 pg/mL [IQR 393-553 pg/mL], $P=.01$ ) and the 


\section{Diagnostic and Prognostic Value of Plasma ADM in COPD Exacerbation}

Table 1. Baseline Characteristics of Subjects Requiring Hospitalization for COPD Exacerbation, Subjects With Stable COPD From an Out-Patient Clinic, and Healthy Controls

\begin{tabular}{|c|c|c|c|}
\hline Characteristics & $\begin{array}{c}\text { Subjects With } \\
\text { COPD Exacerbation }\end{array}$ & $\begin{array}{l}\text { Subjects With } \\
\text { Stable COPD }\end{array}$ & $\begin{array}{l}\text { Healthy } \\
\text { Controls }\end{array}$ \\
\hline Male, $n(\%)$ & $67(84.8)$ & $25(86.2)$ & $15(75.0)$ \\
\hline Age, mean \pm SD y & $67.0 \pm 9.4$ & $64.9 \pm 8.3$ & $61.6 \pm 9.0$ \\
\hline $\mathrm{BMI}$, mean $\pm \mathrm{SD} \mathrm{kg} / \mathrm{m}^{2}$ & $20.9 \pm 3.5$ & $22.3 \pm 3.2$ & $21.9 \pm 1.8$ \\
\hline Percent predicted $\mathrm{FEV}_{1}$, mean $\pm \mathrm{SD}$ & $35.05 \pm 17.98^{*}$ & $34.94 \pm 13.18$ & $103.3 \pm 8.42$ \\
\hline $\mathrm{FEV}_{1} / \mathrm{FVC}$, mean $\pm \mathrm{SD}$ & $0.45 \pm 0.13^{*}$ & $0.37 \pm 0.09$ & $0.80 \pm 0.04$ \\
\hline Smoking, median pack-years (IQR) & $30(0-45)$ & $42(30-60)$ & $30(6.5-34.5)$ \\
\hline COPD duration, median mo (IQR) & $72(48-120)$ & $84(48-120)$ & ND \\
\hline Exacerbation admissions in previous y, median $n$ (IQR) & $3(1-4)$ & $1(0-3)$ & ND \\
\hline \multicolumn{4}{|l|}{ Severity of COPD, $n(\%)$} \\
\hline GOLD grade 1 (percent predicted $\mathrm{FEV}_{1} \geq 80 \%$ ) & $1(1.7)^{*}$ & 0 & ND \\
\hline GOLD grade $2\left(50 \% \leq\right.$ percent predicted $\left.\mathrm{FEV}_{1}<80 \%\right)$ & $10(17.2)^{*}$ & $5(17.2)$ & ND \\
\hline GOLD grade $3\left(30 \% \leq\right.$ percent predicted $\left.\mathrm{FEV}_{1}<50 \%\right)$ & $10(17.2)^{*}$ & $12(41.4)$ & ND \\
\hline GOLD grade 4 (percent predicted $\mathrm{FEV}_{1}<30 \%$ ) & $37(63.8)^{*}$ & $12(41.4)$ & ND \\
\hline Hospital stay, median d (IQR) & $9(6-13)$ & ND & ND \\
\hline \multicolumn{4}{|l|}{ Exacerbation type, $n(\%)$} \\
\hline Anthonisen type 1 (dyspnea, sputum purulence, sputum volume) & $22(27.8)$ & ND & ND \\
\hline Anthonisen type 2 (two of the above) & $24(30.4)$ & ND & ND \\
\hline Anthonisen type 3 (one of the above and one or more minor findings) & $33(41.8)$ & ND & ND \\
\hline $\mathrm{P}_{\mathrm{aO}_{2}}$, mean $\pm \mathrm{SD} \mathrm{mm} \mathrm{Hg}$ & $79.2 \pm 24.5$ & ND & ND \\
\hline $\mathrm{P}_{\mathrm{aCO}_{2}}$, mean $\pm \mathrm{SD} \mathrm{mm} \mathrm{Hg}$ & $56.7 \pm 16.3$ & ND & ND \\
\hline Leukocyte counts, mean $\pm \mathrm{SD} \times 10^{3} / \mu \mathrm{L}$ & $7.0 \pm 2.9$ & ND & ND \\
\hline C-reactive protein, median mg/L (IQR) & $9.1(3.3-4.0)$ & ND & ND \\
\hline $\begin{array}{l}\text { * Spirometry measurement during hospitalization was available in } 58 \text { subjects. } \\
\text { BMI = body mass index } \\
\text { IQR = interquartile range } \\
\text { GOLD = Global Initiative for Chronic Obstructive Lung Disease } \\
\text { ND = no data }\end{array}$ & & & \\
\hline
\end{tabular}

Table 2. Spearman Correlation Between Clinical, Laboratory Parameters, and Plasma Adrenomedullin Levels of Subjects With COPD Exacerbation on Hospital Admission

\begin{tabular}{lcl}
\hline \hline \multicolumn{1}{c}{ Parameter } & Coefficient & $P$ \\
\hline Age, y & 0.01 & .91 \\
Smoking, pack-years & 0.23 & $.043^{*}$ \\
COPD duration, mo & 0.17 & .14 \\
BMI, kg/m ${ }^{2}$ & -0.21 & .07 \\
Percent predicted $\mathrm{FEV}_{1}$ & -0.18 & .19 \\
GOLD grades & 0.28 & $.031^{*}$ \\
Anthonisen type & 0.12 & .29 \\
$\mathrm{P}_{\mathrm{aO}}$, mm Hg & -0.20 & .10 \\
$\mathrm{P}_{\mathrm{aCO}}$, mm Hg & 0.11 & .39 \\
Leukocyte counts, $\times 10^{3} / \mu \mathrm{L}$ & 0.11 & .33 \\
$\mathrm{C}$ reactive protein, $\mathrm{mg} / \mathrm{L}$ & 0.02 & .90 \\
& & \\
* Statistically significant & & \\
BMI $=$ body mass index & & \\
GOLD $=$ Global Initiative for Chronic Obstructive Lung Disease & \\
\hline
\end{tabular}

stable phase $(200 \mathrm{pg} / \mathrm{mL}$ [IQR $143-308 \mathrm{pg} / \mathrm{mL}], P<.001)$. Furthermore, ADM levels in the stable phase were signif- icantly lower than in the recovery phase $(P<.001)$ (Fig. 1B).

In receiver operating characteristic analysis (Table 3), ADM levels could not be used to differentiate COPD exacerbation from stable COPD (area under the curve 0.43, 95\% CI $0.31-0.55, P=.26$ ); however, they could distinguish between stable COPD and healthy control (area under the curve $0.84,95 \%$ CI $0.73-0.95, P<.001$ ) with a cutoff of $225 \mathrm{pg} / \mathrm{mL}$ (Fig. 2A). Moreover, for the diagnosis of COPD (COPD vs healthy control), ADM had an area under the curve of $0.78(95 \% \mathrm{CI} 0.68-0.88, P<.001)$ with a cutoff of $185 \mathrm{pg} / \mathrm{mL}$ (Fig. 2B). Of note, in subjects with COPD exacerbation $(n=20)$, ADM levels had high diagnostic accuracy in differentiating between exacerbation and the stable phase (area under the curve $0.97,95 \%$ CI 0.93-1.02, $P<.001$ ) (Fig. 2C). Using a cutoff of 360 $\mathrm{pg} / \mathrm{mL}$ for ADM led to a sensitivity of $90.0 \%$, a specificity of $95.0 \%$, a positive likelihood ratio of 18 , and a negative likelihood ratio of 0.11 .

Overall, 12 subjects with COPD exacerbation died during the 6-month follow-up period, and one patient died within the following 6 months. ADM levels on presenta- 


\section{Diagnostic and Prognostic Value of Plasma ADM in COPD Exacerbation}
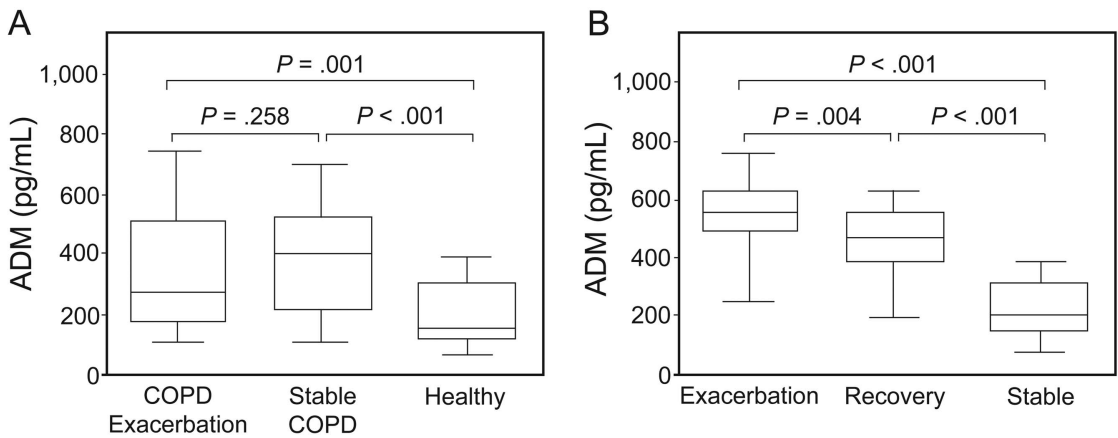

Fig. 1. A: Plasma adrenomedullin (ADM) levels in subjects with COPD exacerbation $(n=79)$, subjects with stable COPD ( $n=29)$, and healthy volunteers $(n=20)$. Compared with healthy subjects $(145 \mathrm{pg} / \mathrm{mL}$ [IQR 103-290 pg/mL]), ADM levels were significantly higher in subjects with COPD exacerbation (270 pg/mL [IQR 170-510 pg/mL], $P=.001)$ and in subjects with stable COPD (400 pg/mL [IQR $210-525$ $\mathrm{pg} / \mathrm{mL}], P<.001)$, but there were no differences between subjects with COPD exacerbation and those with stable COPD $(P=.26)$. B: Plasma ADM levels on hospital admission, in the recovery phase (14-21 d after hospital admission), and in the stable phase (6 months after hospital admission) $(n=20)$. ADM levels were significantly elevated during exacerbation $(560 \mathrm{pg} / \mathrm{mL}[\mathrm{IQR} 495-630 \mathrm{pg} / \mathrm{mL}]) \mathrm{compared}$ with the recovery phase $(470 \mathrm{pg} / \mathrm{mL}$ [IQR $393-553 \mathrm{pg} / \mathrm{mL}], P=.004)$ and the stable phase $(200 \mathrm{pg} / \mathrm{mL}[\mathrm{IQR} 143-308 \mathrm{pg} / \mathrm{mL}], P<.001)$. Furthermore, ADM levels in the stable phase were significantly lower than in the recovery phase $(P<.001)$. The center line represents the median, the box represents the 25th to 75th interquartile range, and the bars represent the 5th/95th percentiles.

Table 3. Diagnostic Accuracy of Plasma Adrenomedullin in Receiver Operating Characteristic Curve Analysis

\begin{tabular}{|c|c|c|c|c|}
\hline & $\begin{array}{l}\text { COPD Exacerbation } \\
\text { vs Stable COPD }\end{array}$ & $\begin{array}{l}\text { Stable COPD vs } \\
\text { Healthy Control }\end{array}$ & $\begin{array}{c}\text { COPD vs } \\
\text { Healthy Control }\end{array}$ & $\begin{array}{c}\text { Exacerbation vs } \\
\text { Stable Phase }\end{array}$ \\
\hline Area under the curve $(95 \% \mathrm{CI})$ & $0.43(0.31-0.55)$ & $0.84(0.73-0.95)$ & $0.78(0.68-0.87)$ & $0.97(0.93-1.02)$ \\
\hline$P$ & 0.26 & $<.001$ & $<.001$ & $<.001$ \\
\hline Cutoff value, $\mathrm{pg} / \mathrm{mL}$ & ND & 225 & 185 & 360 \\
\hline Sensitivity, \% & ND & 72.4 & 72.2 & 90 \\
\hline Specificity, \% & ND & 70.0 & 65.0 & 95 \\
\hline Positive likelihood ratio & ND & 2.41 & 2.06 & 18 \\
\hline Negative likelihood ratio & ND & 0.39 & 0.43 & 0.11 \\
\hline
\end{tabular}

tion did not differ significantly between subjects dying within $1 \mathrm{y}$ after the index hospitalization and long-term survivors ( $380 \mathrm{pg} / \mathrm{mL}$ [IQR $180-480 \mathrm{pg} / \mathrm{mL}$ ] vs $260 \mathrm{pg} / \mathrm{mL}$ [IQR $165-550 \mathrm{pg} / \mathrm{mL}], P=.86)$. In univariate Cox regression analysis, age $(P=.19)$, gender $(P=.31)$, body mass index $(P=.34), \mathrm{P}_{\mathrm{aO}_{2}}(P=.21)$, leukocyte counts $(P=.19)$, percent-of-predicted $\mathrm{FEV}_{1}(P=.32)$, and ADM levels $(P=.97)$ on hospital admission were not associated with 1-y survival, but associations were found for a number of admissions in the previous year (hazard ratio 1.13, 95\% CI 1.01-1.25, $P=.03$ ) and $\mathrm{P}_{\mathrm{aCO}_{2}}$ (hazard ratio 1.06, $95 \%$ CI 1.02-1.09, $P=.001$ ), whereas in multivariate Cox regression analysis, the number of admissions in the previous year (hazard ratio $1.16,95 \%$ CI 1.02-1.32, $P=.030$ ) and $\mathrm{P}_{\mathrm{aCO}}$ (hazard ratio 1.06, 95\% CI 1.03-1.10, $P=.001$ ) were still the independent predictive factors associated with 1-y survival.

A total of 16 subjects $(20.3 \%)$ required ICU treatment and mechanical ventilation or vasopressor therapy. Except for a higher $\mathrm{P}_{\mathrm{aCO}}$ on hospital admission (mean $\pm \mathrm{SD}$
$66.7 \pm 17.7$ vs $53.9 \pm 14.9 \mathrm{~mm} \mathrm{Hg}, P=.01$ ), there were no differences in age, out-patient medication, oxygen saturation, and duration of exacerbation episode between these subjects and the overall cohort, whereas ADM levels were significantly higher in subjects transferred to the ICU compared with those treated in the medical ward $(510 \mathrm{pg} / \mathrm{mL}$ [IQR $253-628 \mathrm{pg} / \mathrm{mL}$ ] vs $230 \mathrm{pg} / \mathrm{mL}$ [IQR $150-465 \mathrm{pg} /$ $\mathrm{mL}], P=.007)($ Fig. 3) and correlated well with ICU stay $(\mathrm{r}=0.32, P=.004)$ and in-hospital stay $(\mathrm{r}=0.41$, $P<.001)$. Hence, a Cox regression analysis was performed to identify predictors of the need for ICU treatment (Table 4). Interestingly, in univariate analysis, only ADM levels accurately predicted the need for ICU care (hazard ratio $1.37,95 \%$ CI $1.09-1.72, P=.008$ ).

\section{Discussion}

In this study, we investigated the diagnostic and prognostic value of plasma ADM levels in subjects with COPD 


\section{Diagnostic and Prognostic Value of Plasma ADM in COPD Exacerbation}
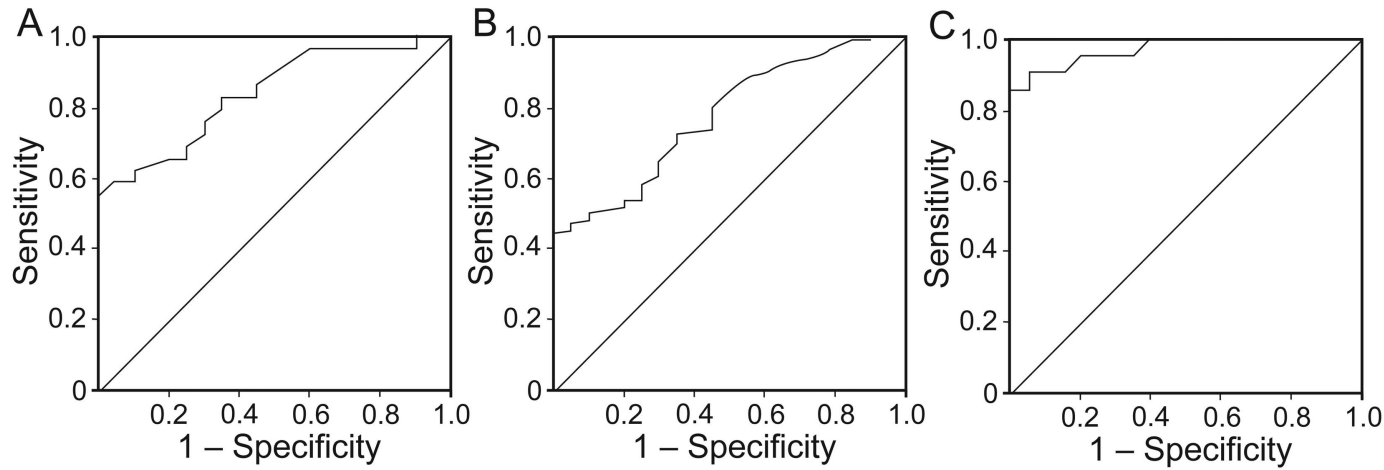

Fig. 2. Diagnostic performance of plasma adrenomedullin (ADM) in receiver operating characteristic curve analysis. A: Plasma ADM was able to differentiate between stable COPD $(n=29)$ and healthy control $(n=20)$ (area under the curve 0.84, 95\% Cl 0.73-0.95, $P<.001)$. B: Plasma ADM could also distinguish between COPD (COPD exacerbation and stable COPD; $n=108)$ and healthy control $(n=20)($ area under the curve $0.7895 \% \mathrm{Cl} 0.68-0.87, P<.001)$. C: For subjects with COPD exacerbation $(n=20)$, plasma ADM had high diagnostic accuracy in differentiating between exacerbation and the stable phase (area under the curve 0.97, 95\% $\mathrm{Cl} 0.93-1.02, P<.001$ ).

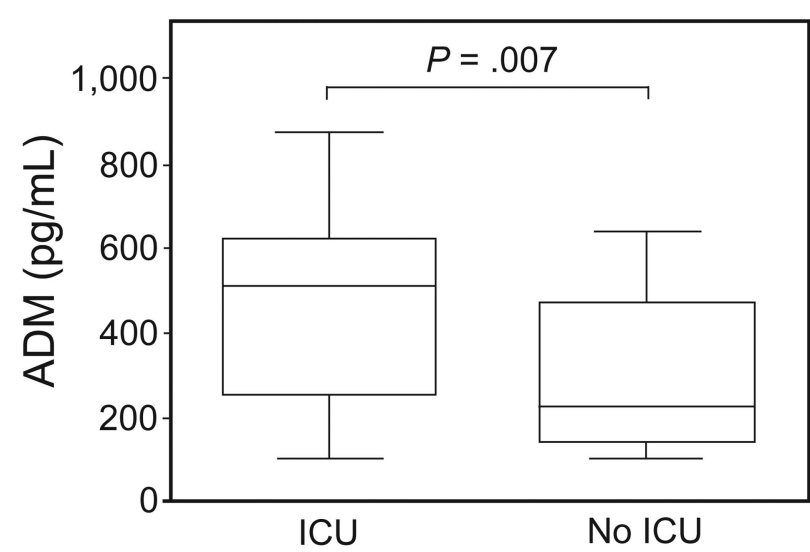

Fig. 3. Plasma adrenomedullin (ADM) levels in subjects requiring ICU treatment $(n=16)$ compared with subjects not requiring ICU treatment $(n=63)(510 \mathrm{pg} / \mathrm{mL}[\mathrm{IQR} 253-628 \mathrm{pg} / \mathrm{mL}] \mathrm{vs} 230 \mathrm{pg} / \mathrm{mL}$ [IQR $150-465 \mathrm{pg} / \mathrm{mL}], P=.007)$. The center line represents the median, the box represents the 25 th to 75 th interquartile range, and the bars represent the 5th/95th percentiles.

exacerbation. Three major findings were reported. First, we found that ADM levels were different among subjects with COPD exacerbation, subjects with stable COPD, and healthy individuals. Second, plasma ADM levels were helpful in differentiating between exacerbation and the stable phase, suggesting that it is an effective biomarker to confirm COPD exacerbation. Finally, ADM levels were significantly higher in subjects requiring ICU treatment and accurately predicted the need for ICU care.

Although a previous study reported that in subjects with COPD exacerbation, ADM levels were markedly increased at exacerbation and decreased significantly in the stable phase, ${ }^{24}$ the diagnostic accuracy of plasma ADM for this disease had not yet been discussed.

This study is the first to explore the diagnostic performance of plasma ADM levels in subjects with COPD ex-
Table 4. Prediction of Need for ICU Treatment in Subjects With COPD Exacerbation by Cox Regression Analysis

\begin{tabular}{lcc}
\hline \hline Parameter (univariate analysis) & Hazard Ratio (95\% CI) & $P$ \\
\hline Age & $0.99(0.95-1.05)$ & .89 \\
BMI & $0.88(0.75-1.04)$ & .13 \\
GOLD grades & $4.24(0.74-24.45)$ & .11 \\
Anthonisen type & $0.98(0.54-1.78)$ & .94 \\
$\mathrm{P}_{\mathrm{aO}}$ & $1.01(0.99-1.03)$ & .53 \\
$\mathrm{P}_{\mathrm{aCO}}$ & $1.04(0.95-1.12)$ & .42 \\
Leukocyte counts & $0.93(0.76-1.13)$ & .46 \\
C-reactive protein & $0.99(0.98-1.01)$ & .49 \\
Adrenomedullin & $1.37(1.09-1.72)$ & .008 \\
\end{tabular}

$\overline{\mathrm{BMI}}=$ body mass index

GOLD $=$ Global Initiative for Chronic Obstructive Lung Disease

acerbation. In our work, the utility of plasma ADM in the diagnosis of COPD exacerbation was examined not only horizontally but also longitudinally. Interestingly, plasma ADM levels could not be used to differentiate between subjects with COPD exacerbation and those with stable COPD, but they could be used to differentiate between subjects with stable COPD and healthy individuals. More importantly, plasma ADM levels had high diagnostic accuracy in differentiating between exacerbation and the stable phase in subjects admitted to the hospital for COPD exacerbation. In 2006, Hurst et al ${ }^{25}$ assessed 36 biomarkers in paired stable and exacerbation plasma samples from 90 subjects with COPD. They found that C-reactive protein was the most selective biomarker in confirming exacerbation; however, its diagnostic accuracy was limited (area under the curve $0.73,95 \%$ CI $0.66-0.8$ ). Compared with C-reactive protein, ADM in our study was sufficiently sensitive and specific for confirming COPD exacerbation (area under the curve $0.97,95 \%$ CI $0.93-1.02$ ). 


\section{Diagnostic and Prognostic Value of Plasma ADM in COPD Exacerbation}

In contrast to our expectations, plasma ADM levels did not predict death in subjects admitted to the hospital for COPD exacerbation. This result was not in line with a previous investigation ${ }^{24}$ that established ADM as a strong predictor of death. The possible explanation for this difference is to assume that the baseline characteristics differed between the 2 cohorts of subjects with COPD exacerbation. About $70 \%$ of subjects included in the previous study had one or more comorbidities, such as diabetes mellitus, renal failure, and malignancy. Of the subjects who died during the follow-up period, $27 \%$ had concomitant malignancy, and $13.5 \%$ of deaths were attributed to a cause other than COPD, whereas in our study, subjects were excluded if they had significant comorbidities, and the main causes of mortality were respiratory conditions (ie, COPD-related respiratory failure or pulmonary hypertension). It is known that ADM can behave both as a hormone and a cytokine. ${ }^{26}$ The inclusion of concomitant comorbidities might complicate the effect of ADM on COPD and confuse its actions on survival. Consequently, we hypothesized that the missing predictive potential of ADM in our work was probably caused by a low prevalence of comorbidities in subjects with COPD exacerbation.

Nevertheless, multivariate Cox regression analysis suggested that the number of admissions in the previous year and $\mathrm{P}_{\mathrm{aCO}}$ on admission are able to adequately predict death in our cohort. This result is consistent with previous studies. Almagro et $\mathrm{al}^{27}$ found that subjects hospitalized on more than one occasion for COPD exacerbation in the previous year had a higher mortality rate compared with other subjects, and mortality increased with the number of hospital admissions. $\mathrm{P}_{\mathrm{aCO}_{2}}$ was a well accepted risk factor for mortality in subjects admitted to the hospital for COPD exacerbation. ${ }^{28}$ The high level of $\mathrm{P}_{\mathrm{aCO}_{2}}$, suggestive of chronic alveolar hypoventilation, reflects the severity of the underlying respiratory condition. ${ }^{29}$ Subjects with chronic hypercapnia often need mechanical ventilation and have a worse prognosis than subjects with normal ventilation.

It is noteworthy that plasma ADM levels on hospital admission correlated significantly with ICU stay and could predict the need for ICU treatment in subjects with COPD exacerbation. This seems to contradict the result obtained for the prediction of death. We assumed that respiratory failure underlying pulmonary disease might contribute to the utility of ADM. Due to hypoxemia or hypercapnia, these subjects were more likely to be treated in the ICU. Previous studies have indicated that hypoxia can up-regulate ADM expression, ${ }^{30}$ so elevated ADM levels may imply the presence of respiratory failure in subjects with COPD and their need for mechanical ventilation.

Several limitations in this investigation should be mentioned. First, this was a single-center observational study; therefore, our results need to be confirmed by conducting a larger and longer study. Second, pulmonary arterial hypertension, a factor known to be related to COPD, was not included in our analysis because the previous study did not find an association between pulmonary arterial hypertension and ADM and did not demonstrate pulmonary arterial hypertension to be associated with increased mortality. ${ }^{24}$ Finally, because we conducted an observational study, we can only hypothesize that measurement of ADM levels on admission will help to identify subjects requiring ICU treatment.

\section{Conclusions}

In summary, plasma ADM is an effective biomarker to confirm COPD exacerbation. Additionally, plasma ADM levels independently predict the need for ICU treatment, although they are not associated with long-term mortality in patients with COPD exacerbation. Therefore, use of ADM in risk stratification could contribute to an improved outcome in patients with COPD exacerbation.

\section{REFERENCES}

1. Lopez AD, Mathers CD, Ezzati M, Jamison DT, Murray CJ. Global and regional burden of disease and risk factors, 2001: systematic analysis of population health data. Lancet 2006;367(9524):17471757.

2. Celli BR, Barnes PJ. Exacerbations of chronic obstructive pulmonary disease. Eur Respir J 2007;29(6):1224-1238.

3. Decramer M, Janssens W, Miravitlles M. Chronic obstructive pulmonary disease. Lancet 2012;379(9823):1341-1351.

4. Verrills NM, Irwin JA, He XY, Wood LG, Powell H, Simpson JL, et al. Identification of novel diagnostic biomarkers for asthma and chronic obstructive pulmonary disease. Am J Respir Crit Care Med 2011;183(12):1633-1643.

5. de Torres JP, Cordoba-Lanus E, López-Aguilar C, Muros de Fuentes M, Montejo de Garcini A, Aguirre-Jaime A, et al. C-reactive protein levels and clinically important predictive outcomes in stable COPD patients. Eur Respir J 2006;27(5):902-907.

6. Rodriguez-Roisin R. Toward a consensus definition for COPD exacerbations. Chest 2000;117(5 Suppl 2):398S-401S.

7. Kitamura K, Kangawa K, Kawamoto M, Ichiki Y, Nakamura S, Matsuo H, Eto T. Adrenomedullin: a novel hypotensive peptide isolated from human pheochromocytoma. Biochem Biophys Res Commun 1993;192(2):553-560

8. Hinson JP, Kapas S, Smith DM. Adrenomedullin, a multifunctional regulatory peptide. Endocr Rev 2000;21(2):138-167.

9. Hayakawa H, Hirata Y, Kakoki M, Suzuki Y, Nishimatsu H, Nagata $\mathrm{D}$, et al. Role of nitric oxide-cGMP pathway in adrenomedullininduced vasodilation in the rat. Hypertension 1999;33(2):689-693.

10. Allaker RP, Zihni C, Kapas S. An investigation into the antimicrobial effects of adrenomedullin on members of the skin, oral, respiratory tract and gut microflora. FEMS Immunol Med Microbiol 1999; 23(4):289-293.

11. Wu R, Zhou M, Wang P. Adrenomedullin and adrenomedullin binding protein- 1 downregulate TNF- $\alpha$ in macrophage cell line and rat Kupffer cells. Regul Pept 2003;112(1-3):19-26. 


\section{Diagnostic and Prognostic Value of Plasma ADM in COPD Exacerbation}

12. Kohno M, Hanehira T, Kano H, Horio T, Yokokawa K, Ikeda M, et al. Plasma adrenomedullin concentrations in essential hypertension. Hypertension 1996;27(1):102-107.

13. Kobayashi K, Kitamura K, Hirayama N, Date H, Kashiwagi T, Ikushima I, et al. Increased plasma adrenomedullin in acute myocardial infarction. Am Heart J 1996;131(4):676-680.

14. Hirayama N, Kitamura K, Imamura T, Kato J, Koiwaya Y, Tsuji T, et al. Molecular forms of circulating adrenomedullin in patients with congestive heart failure. J Endocrinol 1999;160(2):297-303.

15. Kinoshita H, Fujimoto S, Kitamura K, Matsuura Y, Uezono S, Hisanaga S, Eto T. Increased plasma levels of mature adrenomedullin in chronic glomerulonephritis. Nephron 2000;86(3):333-338.

16. Nishio K, Akai Y, Murao Y, Doi N, Ueda S, Tabuse H, et al. Increased plasma concentrations of adrenomedullin correlate with relaxation of vascular tone in patients with septic shock. Crit Care Med 1997;25(6):953-957.

17. Vizza CD, Letizia C, Sciomer S, Naeije R, Della Rocca G, Di Roma A, et al. Increased plasma levels of adrenomedullin, a vasoactive peptide, in patients with end-stage pulmonary disease. Regul Pept 2005;124(1-3):187-193

18. Shah RV, Truong QA, Gaggin HK, Pfannkuche J, Hartmann O, Januzzi JL Jr. Mid-regional pro-atrial natriuretic peptide and proadrenomedullin testing for the diagnostic and prognostic evaluation of patients with acute dyspnoea. Eur Heart J 2012;33(17):2197-2205.

19. Angeletti S, Battistoni F, Fioravanti M, Bernardini S, Dicuonzo G. Procalcitonin and mid-regional pro-adrenomedullin test combination in sepsis diagnosis. Clin Chem Lab Med 2013;51(5):1059-1067.

20. Haaf P, Twerenbold R, Reichlin T, Faoro J, Reiter M, Meune C, et al. Mid-regional pro-adrenomedullin in the early evaluation of acute chest pain patients. Int J Cardiol 2013;168(2):1048-1055.

21. Huang DT, Angus DC, Kellum JA, Pugh NA, Weissfeld LA, Struck $\mathrm{J}$, et al. Midregional proadrenomedullin as a prognostic tool in community-acquired pneumonia. Chest 2009;136(3):823-831.
22. Anthonisen NR, Manfreda J, Warren CP, Hershfield ES, Harding GK, Nelson NA. Antibiotic therapy in exacerbations of chronic obstructive pulmonary disease. Ann Int Med 1987;106(2): 196-204.

23. Global Initiative for Chronic Obstructive Lung Disease. Global strategy for the diagnosis, management, and prevention of chronic obstructive pulmonary disease. Updated 2011. http://www.goldcopd.com. Accessed December 6, 2011.

24. Stolz D, Christ-Crain M, Morgenthaler NG, Miedinger D, Leuppi J, Müller C, et al. Plasma pro-adrenomedullin but not plasma proendothelin predicts survival in exacerbations of COPD. Chest 2008; 134(2):263-272.

25. Hurst JR, Donaldson GC, Perera WR, Wilkinson TM, Bilello JA, Hagan GW, et al. Use of plasma biomarkers at exacerbation of chronic obstructive pulmonary disease. Am J Respir Crit Care Med 2006;174(8):867-874.

26. Linscheid P, Seboek D, Zulewski H, Keller U, Müller B. Autocrine/ paracrine role of inflammation-mediated calcitonin gene-related peptide and adrenomedullin expression in human adipose tissue. Endocrinology 2005;146(6):2699-2708.

27. Almagro P, Calbo E, Ochoa de Echagüen A, Barreiro B, Quintana S, Heredia JL, Garau J. Mortality after hospitalization for COPD. Chest 2002;121(5):1441-1448.

28. Seneff MG, Wagner DP, Wagner RP, Zimmerman JE, Knaus WA. Hospital and 1-year survival of patients admitted to intensive care units with acute exacerbation of chronic obstructive pulmonary disease. JAMA 1995;274(23):1852-1857.

29. Groenewegen KH, Schols AM, Wouters EF. Mortality and mortality-related factors after hospitalization for acute exacerbation of COPD. Chest 2003;124(2):459-467.

30. Hofbauer KH, Jensen BL, Kurtz A, Sandner P. Tissue hypoxygenation activates the adrenomedullin system in vivo. Am J Physiol Regul Integr Comp Physiol 2000;278(2):R513-R519. 